\title{
Protée
}

\section{Présentation : Esthétiques numériques. Textes, structures, figures}

\section{Bertrand Gervais et Alexandra Saemmer}

Volume 39, numéro 1, printemps 2011

URI : https://id.erudit.org/iderudit/1006722ar

DOI : https://doi.org/10.7202/1006722ar

Aller au sommaire du numéro

Éditeur(s)

Département des arts et lettres - Université du Québec à Chicoutimi

ISSN

0300-3523 (imprimé)

1708-2307 (numérique)

Découvrir la revue

Citer ce document

Gervais, B. \& Saemmer, A. (2011). Présentation : Esthétiques numériques.

Textes, structures, figures. Protée, 39(1), 5-8. https://doi.org/10.7202/1006722ar d'utilisation que vous pouvez consulter en ligne.

https://apropos.erudit.org/fr/usagers/politique-dutilisation/ 
PRÉSENTATION

\title{
Esthétiques numériques Textes, structures, figures
}

\author{
Bertrand Gervais et AleXandra Saemmer
}

l MAGINONS, nous proposent Alexander S. Galloway et Eugene Thacker, une exposition artistique de virus informatiques (2007: 105 et suiv.). À quel type de commissariat donnerait-elle lieu? Quels en seraient les principes? L'exposition consisterait-elle en une abondante documentation sur les virus les plus importants ou en exemples de virus à l'œuvre in situ? Ressemblerait-elle plus à des archives ou à un zoo? Et que faire des «restes» laissés par les virus après leur passage dévastateur? Un réseau serait sûrement requis, dont la principale fonction serait de réitérer les séquences de contagion et de réduplication. Des ordinateurs seraient sacrifiés, afin de montrer le processus de contagion. De telles propositions existent déjà, nous expliquent les auteurs. À la Biennale de Venise en 2001, les collectifs 0100101110101101.org et epidemiC ont proposé comme œuvre le virus informatique Biennale.py. L'œuvre a été reprise par Francesca Nori en 2004, dans le cadre de l'exposition «I love you » sur les virus informatiques. Cet exemple «épidémique» signale clairement que la culture numérique se déploie dans des directions inattendues qui nous forcent à renouveler nos catégories esthétiques, voire notre vocabulaire. Comment désigner cette pratique artistique, sans faire entrer les notions d'avant-garde ou d'art contemporain? Comment décrire les transformations que subissent les textes par la voie de leur électrification? Quel est le statut de ces œuvres ouvertes (la notion d'Umberto Eco n'a jamais paru aussi pertinente)?

Dans The Laws of Cool (2004), Alan Liu parle volontiers d'une esthétique virale, où la distinction entre production et destruction est brouillée. Le viral est le mode par excellence de propagation du Web, qui repose pour certains sur la transmission de «mèmes ». À la suite de Liu, on peut aussi parler d'une esthétique « férale», où la frontière entre le domestiqué et l'ensauvagé est franchie, lieu de détournements et de réappropriations. C'est toute la culture remix qui s'inscrit dans cette mouvance. Pour Peter Lunenfeld, les explorations numériques dépendent d'une esthétique du non-fini, où tout est en perpétuelle recomposition (1999: 10).

Mais, dans les faits, cet état de non-fini est d'emblée inscrit dans toute œuvre numérique, à travers sa labilité notoire explorée et théorisée depuis le début des années 2000 par les artistes du «Transitoire Observable». Fortement dépendantes des outils informatiques avec lesquels elles ont été créées, les œuvres numériques sont susceptibles de se transformer avec chaque changement de vitesse de calcul des microprocesseurs, chaque nouvelle génération de logiciels. Certaines œuvres textuelles animées, créées dans les années 1990, passent aujourd'hui sur l'écran à une vitesse qui les rend illisibles. Cette instabilité inéluctable pose le problème de l'archivage et de la préservation, incitant à réfléchir sur les cadres de l'œuvre numérique, sur ses limites, ses parties constitutives et ses modalités d'existence. Les difficultés ne sont pas que conceptuelles, liées à la nécessité de proposer un vocabulaire critique et des stratégies d'analyse adaptés; elles sont aussi techniques, sujettes à l'instabilité d'une technologie en constante transformation. Et elles ont suscité, de la part des artistes, différentes réponses esthétiques, qui vont d'une ignorance volontaire de cette instabilité jusqu'à son inscription dans l'œuvre comme principe esthétique fondateur. 


\section{EXPLORATIONS NUMÉRIQUES}

Les œuvres numériques apparaissent comme des formes hybrides et instables. La littérature électronique, la poésie générative, les textes numériques, le Net Art et les expérimentations hypermédiatiques diffusées dans le cyberespace représentent un ensemble hétérogène d'œuvres où se réunissent textes, images, séquences vidéo, animations numériques et processus algorithmiques, et elles participent tout autant de la littérature que de l'art, du cinéma, de la vidéo et du théâtre. Pour en parler, nous avons choisi de les inscrire sous la bannière générale des esthétiques numériques, regroupant l'ensemble des pratiques et des créations artistiques rendues possibles par les développements du numérique et de l'ordinateur graphique.

Une des particularités de ces créations est que les textes qui les constituent sont initialement perçus comme des images, constituant ainsi des «figures» animées et manipulables de l'écrit. Les textes et les documents deviennent leur propre figure: ils ne se lisent plus, ou plus seulement; ils se donnent en spectacle, deviennent touchables, «manipulables». Ils sont intégrés à des signes plus complexes combinant plusieurs sémiotiques, qui se laissent regarder et contempler comme des totalités. Les mots ont valeur non plus uniquement de signes linguistiques, mais d'images ou d'icônes, voire de rythmes, mouvants et touchables. Ce sont leurs aspects formels en tant que « figures », leur disposition sur la page-écran, leur accumulation et le traitement informatique qui leur a été accordé dans le programme qui deviennent signifiants. Or, ces figures se déploient dans de nombreuses directions, qui accentuent tantôt leur aspect graphique ou leur complexité, tantôt leur fluidité, leur caractère nécessairement changeant, leur manipulabilité, leur caractère algorithmique. Des questions, que l'on croyait réglées, se posent à nouveau: quel est le statut de ces textes et de ces documents, quelle valeur accorder aux écrits que le numérique rend instables, quels régimes de représentation marquent l'époque contemporaine?

Les arts hypermédiatiques participent d'une virtualisation des pratiques littéraires et artistiques, qui supposent une transformation en profondeur de la notion d'œuvre. Beaucoup d'auteurs dans ce dossier posent ainsi la question de savoir où se situent la littérarité, la poéticité ou l'artisticité de l'œuvre numérique. La contribution de René Audet et de Simon Brousseau cherche à en identifier les éléments dans deux projets à caractère littéraire. Le Tiers Livre de François Bon et Désordre de Philippe De Jonckheere peuvent être considérés comme des œuvres emblématiques d'une esthétique définie à la fois par la diffraction des contenus et par une accumulation archivistique. La temporalité y devient de façon métaphorique la matière même du texte. Aux antipodes de la fixité et du caractère « inscrit » du support imprimé, le support numérique permettrait une représentation dynamique des phénomènes mémoriels, admettant non seulement le souvenir, mais aussi la transformation, voire l'oubli dans ses formes changeantes, explorant le flux des données du Web. Deux figures d'une poétique du numérique émergent en particulier des analyses du Tiers Livre et de Désordre: le lien hypertexte comme extension significative et signifiante du texte, et le «détournement» des formes et formats conventionnels du discours numérique. En particulier dans Désordre, les principes de la base de données et du lien sont utilisés non pas pour ordonner les contenus et aider le lecteur à se repérer dans le matériau textuel, mais pour l'égarer, le perdre, jouant avec ses attentes. Les deux projets développent ainsi une réflexion sur la mémoire et l'expérience du quotidien qui est profondément modelée par les caractéristiques du support numérique qui les accueille.

En insistant sur ces caractéristiques fluides, voire instables, René Audet et de Simon Brousseau proposent un cadre de lecture possible pour les deux articles suivants, qui s'intéressent cependant moins à la structure des sites analysés qu'à des micro-phénomènes de sens. Les figures de style héritées du texte linguistique ont parfois été mobilisées pour approcher les phénomènes de sens émergeant des ensembles «pluricodes » caractérisés par la convergence de plusieurs sémiotiques: le texte, l'image, le mouvement, le son, la manipulation... Ce transfert semble pourtant problématique, justement à cause de la nature pluricode de ces ensembles. Avant de développer une nouvelle taxinomie, il faut commencer par décrire avec précision les unités sémiotiques impliquées et analyser les mécanismes de construction de sens à l'œuvre. Convoquant une méthodologie sémio-rhétorique déve- 
loppée dans le cadre d'un projet de recherche commun (impliquant également Philippe Bootz et Jean Clément), les deux auteurs suivants reviennent également sur la question des attentes du lecteur, nourries entre autres par les conventions émergentes du discours numérique, et que certaines figures perturbent, inquiètent ou déroutent.

Tout en insistant sur le fait que les conventions du discours numérique sont loin d'être stabilisées, Alexandra Saemmer avance dans son article que le différentiel avec les attentes du lecteur se situe entre autres dans les figures d'animation et les figures de manipulation, et que ce différentiel, que l'on pourrait appeler le style d'une œuvre numérique, constitue un important facteur de «littérarité». Après avoir identifié un certain nombre d'unités sémiotiques du mouvement, leurs traits d'iconicité et leur potentiel signifiant, l'auteure analyse les «couplages » entre les significations potentiellement associées à un texte ou une image et un mouvement en fonction du contexte de lecture, et elle propose une modélisation du mécanisme de la construction de sens. L'interprétation des exemples puisés dans la publicité et la littérature numériques montre que même un couplage d'apparence conventionnel entre mouvement et texte (par exemple le mot «bombe» qui clignote) peut se révéler riche en possibilités d'interprétation. Ces possibilités se démultiplient néanmoins dans le cas du couplage non conventionnel. Une part de la littérarité des œuvres numériques se situe ainsi dans le jeu avec les contraintes, les règles et les conventions du discours numérique, dans des projets artistiques situés aux antipodes des productions de masse de l'industrie culturelle.

Serge Bouchardon reprend la réflexion sur les micro-phénomènes de sens dans le discours numérique en s'intéressant plus particulièrement aux figures de manipulation. C'est moins la fonction liante, structurante ou déstructurante du lien hypertexte, qui est analysée dans cet article, que le sens qu'un geste de manipulation peut prendre dans l'interaction en fonction du contexte. À la suite de Jean-Louis Weissberg (2006) et d'Yves Jeanneret, Serge Bouchardon rappelle que le fait d'effectuer un geste comme le clic sur un mot ou une image est déjà un acte d'interprétation. Ces dernières années, grâce à l'émergence de nouveaux dispositifs d'interaction dans le jeu vidéo et au succès des tablettes numériques et autres iPhone, le répertoire de gestes s'est diversifié. Ainsi, l'action du lecteur est considérée comme un énoncé de gestes (par exemple le glisser/déposer - drag and drop), et cette action a elle-même une signification plus globale liée à un double couplage à un contexte et à un processus. Alors que les couplages conventionnels confortent les attentes du lecteur, nourries entre autres par les conventions émergentes du discours numérique, les couplages non conventionnels mettent ces attentes au défi.

Dans son article consacré à l'adaptation transmédiatique de Fidget de Kenneth Goldsmith, Yan Rucar explore aussi cette question du couplage. Initialement fixe et stable, le texte de Fidget est fragmenté dans sa version numérique; devenu animé et manipulable, chaque élément textuel est détaché de son contexte; objet autonome qui se déplace sur l'écran avant de disparaître, il se caractérise par un balancement du signifiant entre système linguistique et iconicité qui met en danger la lisibilité du texte. En s'animant, les fragments textuels s'offrent ainsi comme un «autre langage» qui, d'apparence, complète et prolonge, mais finalement déborde les signes écrits. La jonction entre deux "organisations de sens », le mouvement et le texte linguistique, s'avère impossible dans cette œuvre. Caractéristique de beaucoup d'œuvres de littérature numérique, la coexistence entre les sémiotiques visuelle, temporelle et linguistique s'observe aussi dans certaines créations pré-numériques relevant notamment de la poésie visuelle. En enrichissant son analyse de Fidget de cette mise en contexte historique, Yan Rucar offre également un cadre de lecture complémentaire aux approches sémio-rhétoriques déjà citées.

Après les contributions dans ce dossier consacrées aux structures, formes et figures animées et manipulables, Jean Clément revient sur une autre spécificité fondamentale de la littérature et de l'art électroniques: la question de l'aléatoire et du hasard. Si cette question traverse toute l'histoire de la littérature, c'est Un coup de dés jamais n'abolira le hasard de Mallarmé qui contient la problématique centrale de son article: le monde physique est soumis à la loi du hasard; la création poétique se donne pour tâche de vaincre le hasard «mot à mot»; mais ce travail est lui-même soumis aux aléas de l'inspiration, symbolisés par le coup de dés. L'aléatoire peut-il alors 
vaincre le hasard? À partir de cette question centrale, Clément propose une typologie des formes du hasard et de l'aléatoire dans la littérature, et étudie le rôle que jouent ces deux concepts dans la création, la réception des œuvres et l'émergence du sens. Dans la littérature numérique, l'aléatoire peut certes donner lieu à des productions imprimables. Néanmoins, l'ordinateur joue pleinement son rôle lorsqu'il multiplie les textes instantanément et jusqu'à l'infini. Plus que de les donner à lire, ce mécanisme fait apparaître le caractère génératif de l'œuvre tout en l'inscrivant dans une esthétique de l'éphémère.

Si la littérature numérique est caractérisée par un jeu sur la forme, elle s'avère donc aussi éminemment politique, comme le montre la contribution de Samuel Archibald consacrée au documentaire « détourné » Nothing So Strange de Brian Flemming. Le film est consacré aux événements suivant I'«attentat » du 2 décembre 1999 contre Bill Gates, fondateur et président de Microsoft. Il détaille les activités d'un groupe de pression conspirationniste, Citizens for Truth, qui cherche à faire la lumière sur l'événement. Inspiré d'un «vrai » travail de recherche documentaire sur les grands assassinats politiques de l'histoire américaine récente et les milieux conspirationnistes, Nothing So Strange s'interroge sur deux aspects de la culture contemporaine: la transformation des communautés d'intérêts induite par I'utilisation d'Internet et le statut trouble des documents sur le Web. Suivant jusqu'au bout sa propre logique, ce projet artistique parasite également l'espace Internet en y imposant des textes et des artéfacts issus de sa propre fiction. Une œuvre participative dérive du film de Flemming: cinéastes, spectateurs et internautes ont détourné la capacité documentaire de l'archive filmique et numérique, afin de se réapproprier la figure historique du complot meurtrier, mettant en œuvre une esthétique que le réalisateur lui-même qualifie de realityhacking et qui remet en question l'espace de jeu entre réalité et fiction.

L'esthétique du non-fini et du viral se trouve pleinement actualisée dans les détournements et les fictions de flux, explorés par Bertrand Gervais et Anaïs Guilet en clôture de ce dossier. Le flux donne lieu à des œuvres ouvertes qui n'existent qu'en tant que processus en acte. Ceux qui vont mourir de Grégory Chatonsky en est l'exemple idoine. L'œuvre détourne des sites de partage de photographies ou d'écrits pour composer un flot continu d'images où musiques, photographies et phrases entrent en relation. Les figures générées sont essentiellement imprévisibles et instables, jouant sur des fluctuations constantes de signes. Le flot d'informations du cyberespace en est le matériau même: il est détourné et fictionnalisé, transformé en œuvres singulières, nécessairement ouvertes sur le réseau, parce qu'elles ne peuvent exister qu'en son sein, mais étrangement autistes, puisque refermées sur elles-mêmes. Elles multiplient leurs calculs à l'infini, indifférentes à l'internaute qui en contemple les résultats. En fait, l'abondance, la succession et la répétition des signes sapent la signification et perdent l'internaute dans un trop-plein d'information. Elles suscitent, à tout le moins, une étonnante entropie symbolique, dont il faut tenir compte dans toute évaluation des formes contemporaines de l'expérience.

Pour comprendre la spécificité des esthétiques numériques, les articles de ce dossier s'inscrivent ainsi entre deux bornes: celle plus large des explorations hypermédiatiques, celle plus resserrée des interfaces et surfaces écraniques. Ces bornes permettent de discuter des fonctionnalités et du statut des œuvres dans un régime de représentation et de transmission numérique, de décrire des stratégies et procédés de création spécifiques à ce régime et de rendre compte ultimement de l'impact de l'interactivité, dans ses aspects médiatique, sémiotique et symbolique. Elles permettent aussi de baliser une esthétique dont l'essor risque de modifier considérablement notre rapport à la littérature et aux arts.

Galloway, A. S. et E. THACKER [2007]: The Exploit. A Theory of Networks, Minneapolis/Londres, University of Minnesota Press. LIU, A. [2004] : The Laws of Cool: Knowledge Work and the Culture of Information, Chicago, University of Chicago Press. LUNENFELD, P. [1999]: The Digital Dialectic: New Essays on New Media, Cambridge et London, The MIT Press.

TRANSITOIRE OBSERVABLE (regroupement d'artistes numériques). En ligne: http://transitoireobs.free.fr/to/ (page consultée le 7 mars 2011). 